\title{
Role of Music in a Plastic Surgery Setting: A Systematic Review and Meta-analysis
}

\author{
James A. Zapata-Copete ${ }^{1,2,3}$ \\ ${ }^{1}$ UROGIV Research Group at Universidad del Valle, Cali, Colombia \\ ${ }^{2}$ Department of Epidemiology, Universidad Libre, Cali, Colombia \\ ${ }^{3}$ Department of Plastic Surgery, Universidad del Valle, Cali, \\ Colombia \\ ${ }^{4}$ School of Medicine at Universidad del Valle, Cali, Colombia \\ Indian J Plast Surg 2019;52:160-165
}

Maria Juliana Cordoba-Wagner ${ }^{1}$

Herney Andrés García-Perdomo $0^{1,2,4}$

\author{
Address for correspondence James A. Zapata-Copete, MD, \\ Department of Epidemiology, Universidad Libre-Cra. 37a \#3-29, \\ Cali, Colombia (e-mail: james.zapata@correounivalle.edu.co).
}

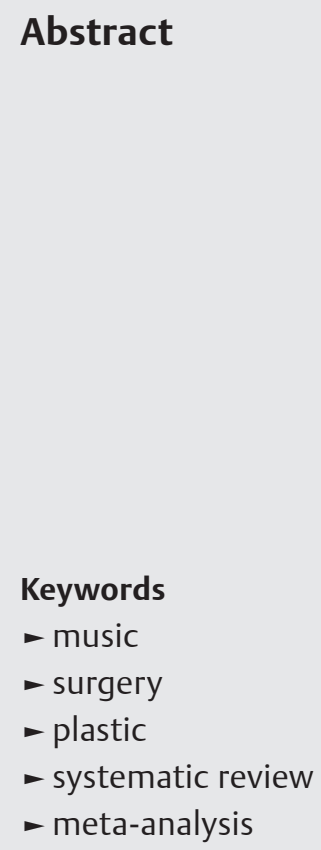

Objective To assess the effectiveness and harm of music to reduce anxiety and pain in a plastic surgery setting.

Materials and Methods A search strategy was conducted in the MEDLINE, CENTRAL, EMBASE, and LILACS databases. Searches were also conducted in other databases and unpublished literature. Clinical trials were included without language restrictions. The risk of bias was evaluated with the Cochrane Collaboration's tool. An analysis of random effects was conducted. The primary outcomes were anxiety and pain. The secondary outcomes were length of stay, physiological parameters, and adverse effects. The measure of the effect was the mean difference (MD) and standardized MD (SMD) with a $95 \%$ confidence interval $(\mathrm{Cl})$. The planned interventions were music versus no music. Results Four articles were included in the qualitative and quantitative analysis. A total of 306 patients were found among the four studies. A low risk of bias was shown for most of the study items. The overall standardized mean difference (SMD) for anxiety $-3.64[95 \% \mathrm{Cl}-5.71$ to $-1.56(p$-value $=0.0006)]$ favoring music compared with no intervention, and for pain the mean difference (MD) was $-12.06[95 \% \mathrm{Cl}-33.47$ to 9.35 ( $p$-value $=0.2696)$ ] showing no statistical differences.

Conclusion Playing music is a safe and free intervention that diminishes anxiety in patients who undergo plastic surgery procedures.

\section{Introduction}

Historically, listening to music has been a source of pleasure for the human being. Thus, a large number of music genres have been heard in many human activities, including the clinical field and consequently the operating theaters with a long history. ${ }^{1}$ This might be seen as a relaxing "distraction" for patients and health workers; nonetheless, since the mid20th century, researchers have found a specific role as a therapeutic intervention. ${ }^{2}$

It is well documented that hospitals and clinics are anxiogenic and stressful environments and this is the reason why many interventions have been studied to decrease anxiety and stress. Nowadays, interest in music has been growing and consequently several studies have investigated its effect on emotions and neurophysiology. ${ }^{3-5}$ As an intervention, music has shown to be effective in improving physical signs, decreasing stress hormones, and stabilizing vital signs. ${ }^{1,6-8}$ In a recent systematic review and meta-analysis, Vetter et $\mathrm{al}^{9}$ described a positive effect of music in pain and anxiety in surgical patients, likewise in physiological parameters and vital signs. This emerging information allows us to say that music could be accepted as a noninvasive, inexpensive, harmless, and useful complementary intervention ${ }^{10}$ to diminish pain and anxiety, to improve physical and vital signs, and to enhance the satisfaction in what people are experiencing. ${ }^{11,12}$

Plastic surgeries have an implicit and known aesthetic component, which could increase the anxiety and stress
DOI https://doi.org/

10.1055/s-0039-1696792

ISSN 0970-0358.
License terms

$\circledast(1) \Theta \circledast$ 
inherent in surgical procedures. Despite the results and growing evidence of music and its clinical use, there is no consensus about the role played by music in plastic surgery. Experience in medicine has shown that knowledge is not always transposable between medical specialties; therefore, we performed this study to assess the effectiveness and harms of music to reduce anxiety and pain in a plastic surgery setting.

\section{Methods}

We performed this review according to the recommendations of the Cochrane Collaboration and following the PRISMA Statement. The PROSPERO registration number is CRD42017076935. ${ }^{13}$

\section{Eligibility Criteria}

We included clinical trials, involving the assessment of the effect of music on plastic surgery. The intervention was applying music as a therapeutic intervention within 24 hours around the surgical procedure. It could be preoperative, during anesthetic induction, during the procedure, or in the postoperative period. Therefore, the comparison was: music versus no intervention or placebo. There were no timing restrictions nor setting or language restrictions. The exclusion criteria were sounds other than music.

\section{The Primary Outcomes}

Pain and anxiety measured by any scale.

\section{The Secondary Outcomes}

(1) Length of stay measured by any scale of time; (2) physiological parameters such as blood pressure, heart rate, and respiratory rate measured by any scale, and (3) adverse effects.

\section{Information Sources}

A search strategy was designed for clinical trials published in MEDLINE (Ovid), CENTRAL (Cochrane Library), LILACS, and EMBASE databases from inception to July 2017. The search strategy was specific for each database and included a combination of medical headings and free text terms for plastic surgery and music (-Supplementary Material; online only). A specific search was performed with indexed terms and free writing for sources of conference abstracts, clinical trials in progress (www.clinicaltrials.gov), literature published in nonindexed journals, and other sources of gray literature. We contacted authors by e-mail in case of missing information. No language restrictions were used, and the publication status of the articles was not considered.

\section{Data Collection}

Two researchers reviewed each reference by title and abstract. Then we scanned full texts of relevant studies, applied prespecified inclusion and exclusion criteria, and extracted the data. Disagreements were resolved by consensus, and when discrepancy could not be solved, a third reviewer resolved the conflict.
Relevant data was collected in duplicate by using a standardized data extraction sheet that contained the following information: author names, title, year of publication, study design, geographic location, objectives, inclusion and exclusion criteria, number of patients included, losses to follow-up, timing of music, kind of music, who chose the music, kind of procedure, definitions of outcomes, outcomes and association measures, and funding source.

\section{Risk of Bias}

The assessment of the risk of bias for each study was made using the Cochrane Collaboration tool which covers sequence generation, allocation concealment, blinding, incomplete outcome data, selective reporting, and other biases. ${ }^{14}$ Two independent researchers judged about the possible risk of bias from extracted information, rating it as "high risk," "low risk," or "unclear risk." We computed a graphic representation of potential bias using a Review manager software (RevMan version 5.3; Nordic Cochrane Centre, Cochrane Collaboration, United Kingdom).

\section{Data Analysis/Synthesis of Results}

We performed the statistical analysis in R. ${ }^{15}$ For continuous outcomes, we reported information for pain using the mean difference (MD) with 95\% confidence intervals (CIs), for anxiety we reported information with standardized MD (SMD), and we pooled the information with a random-effect meta-analysis according to the heterogeneity expected. We reported the results in forest plots for the main outcome. Heterogeneity was evaluated using the $I^{2}$ test. For the interpretation, less than $50 \%$ correspond to low heterogeneity and more than $50 \%$ correspond to high levels of heterogeneity, respectively.

\section{Publication Bias}

We did not perform publication bias due to the small number of included studies for each outcome.

\section{Sensitivity Analysis}

We performed sensitivity analysis extracting weighted studies and running the estimated effect to find differences. Meta-regression was not performed since no data were available to achieve it. No other sensitivity analysis was performed.

\section{Subgroup Analysis}

We planned a subgroup analysis by time and selection of the intervention, kind of music, and procedure. However, it was not possible due to lack of studies.

\section{Results}

We found 1,455 records through the electronic search strategy and seven studies through other searches. After excluding duplicates, we assessed 936 records. Finally, four studies were included and described in our qualitative and quantitative analysis ${ }^{16-19}$ ( - Fig. 1). 


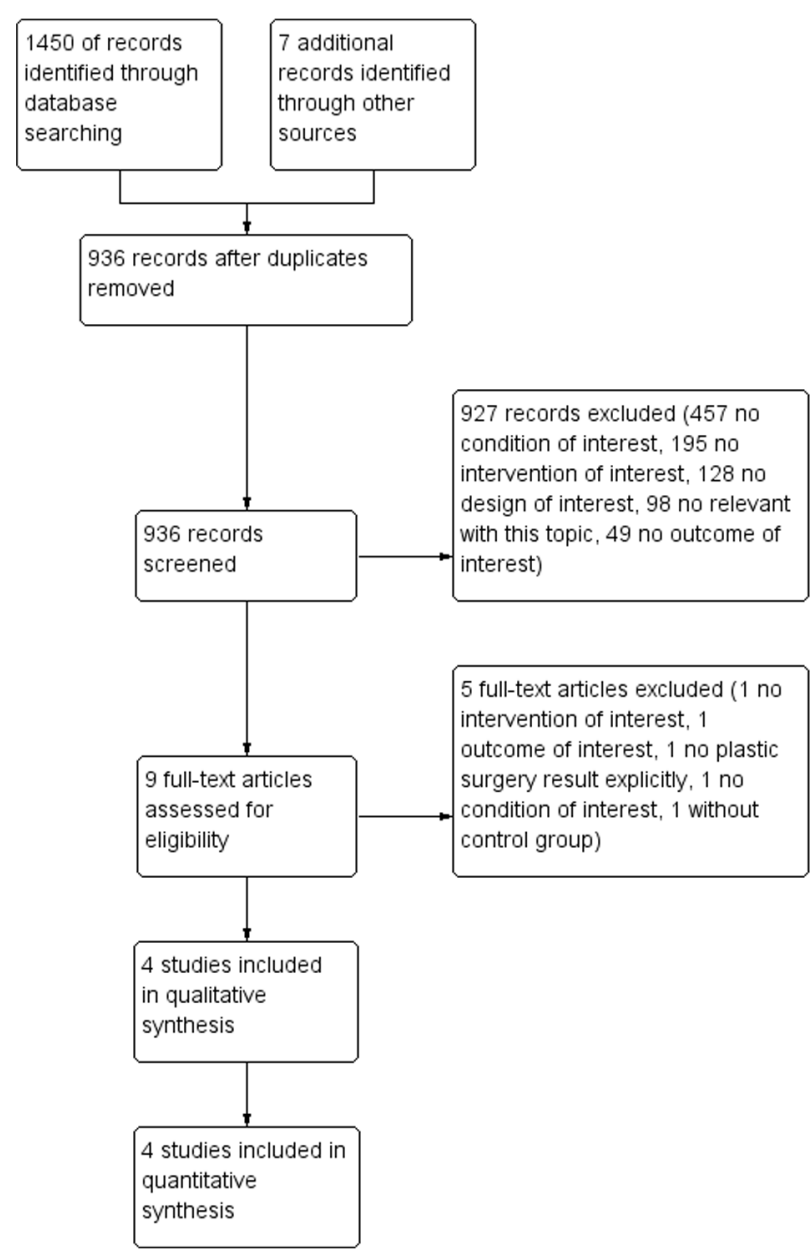

Fig. 1 Flowchart of included studies.

\section{Included Studies}

A total of 306 patients were included in our analysis with a mean of 76 patients per study. All the studies were conducted in different countries: United States, ${ }^{16}$ Scotland, ${ }^{17}$ England, ${ }^{18}$ and Iran. ${ }^{19}$ Three studies played music during the intervention $^{16-18}$ and one of them played music 20 minutes once a day for 3 consecutive days before wound care procedures. ${ }^{19}$ Although in different types, classical music was available in all the studies, additionally. Menegazzi et $\mathrm{al}^{16}$ had available 50 different styles and artists (-Table 1).

\section{Excluded Studies}

$\mathrm{Ni}$ et al's study ${ }^{20}$ assessed the effect of music on preoperative anxiety for day surgery patients; it showed that plastic surgery accounts for the largest number of patients. However, outcomes were exposed to different types of surgeries jointly. It was excluded since there was no answer for e-mails. The study of Updike and Charles ${ }^{21}$ was excluded since it was a quasi-experimental study and no control group was present.

\section{Risk of Bias Assessment}

One study had a high risk of selection bias (random sequence generation and allocation concealment), ${ }^{17}$ two of them had an unclear risk classification for this bias, ${ }^{16,19}$ since it was not appropriately described. The remaining was classified as low risk of bias (-Fig. 2). No unweighted $K$ for risk of bias between two reviewers was observed.

\section{Effect of Interventions Primary Outcomes}

All the studies assessed the effect of music in anxiety. Therefore, we performed a meta-analysis. We found a SMD of $-3.64(95 \% \mathrm{CI}-5.71$ to -1.56 [ $p$-value $=0.0006])$ (I2 $=97.03 \%$ [ $p$-value $<0.0001]$ ) favoring music (-Fig. 3 ).

Two studies assessed the effect of music in pain16,19, in the meta-analysis we found a MD of $-12.06(95 \% \mathrm{CI}-33.47$ to 9.35 [ $p$-value $=0.2696])(\mathrm{I} 2=99.36 \%[p$-value $<0.0001])$, showing no statistical differences.

\section{Secondary Outcomes}

Regarding physiological variables, data from two studies 16,18 allowed us to perform a meta-analysis for respiratory rate, we found MD -1.31 (95\%CI -2.68 to 0.05 [ $p$-value $=0.0598]$ ) $(\mathrm{I} 2=91.20 \%[p$-value $=0.0007])$, without finding statistical differences. Menegazzi et al ${ }^{16}$ additionally assessed other physiological variables (music and no-music), they measured heart rate (before, $78.0 \pm 14.3$ and $84.9 \pm 10.7$; after, $77.3 \pm 10.2$ and $74.8 \pm 9.3$, respectively), systolic blood pressure (before, $126.1 \pm 14.5$ and $126.6 \pm 25.0 \mathrm{~mm} \mathrm{Hg}$; after, $123.1 \pm 17.5$ and $117.7 \pm 13.3 \mathrm{~mm} \mathrm{Hg}$ ), diastolic blood pressure (before, $79.4 \pm 11.5$ and $73.8 \pm 11.2 \mathrm{~mm} \mathrm{Hg}$; after, $76.9 \pm 10.8$ and $73.5 \pm 11.8 \mathrm{~mm} \mathrm{Hg}$ ). None of the between-group differences were statistically significant.

\section{Discussion}

This is the first systematic review and meta-analysis assessing the effect of music in a plastic surgery setting. We found a benefit of music as a safe and free intervention: reducing anxiety in patients who underwent plastic surgery. However, with the available data, no differences were found in pain and physiological variables when music was played, it could be attributed to the low number of studies and patients involved in the studies assessed.

The publication of Updike and Charles ${ }^{21}$ was the first study assessing the effect of music on plastic surgery patients. They played music for patients awaiting an elective plastic surgery procedure, finding an improvement in the emotional condition, heart rate, and blood pressure after the end of music. These results were congruent with the results of Ghezeljeh et al's study, ${ }^{19}$ who played music preoperatively for burned patients, finding lesser levels of pain and anxiety after procedures in patients who listened to music. Such results were also found in studies that played music during a procedure in most of the included studies.

In a recent systematic review and meta-analysis, the effect of art on surgical patients was assessed. Regarding music, the researchers found a positive effect on pain, necessity of pain medication, anxiety, systolic blood pressure, and heart rate. However, they found no differences in physiological variables (systolic blood pressure and heart rate) and pain medication 
Table 1 Characteristics of included studies

\begin{tabular}{|c|c|c|c|c|c|c|c|c|}
\hline Author & Country & $\begin{array}{l}\text { Type of } \\
\text { procedure }\end{array}$ & $\begin{array}{l}\text { Music } \\
\text { selected } \\
\text { by }\end{array}$ & Kind of music & Timing & Outcome & $\begin{array}{l}\text { Scale for pain/ } \\
\text { anxiety }\end{array}$ & $\begin{array}{l}N \text { Intervention: } \\
\text { control }\end{array}$ \\
\hline $\begin{array}{l}\text { Menegazzi } \\
\text { et al (1991) }\end{array}$ & $\begin{array}{l}\text { United } \\
\text { States }\end{array}$ & $\begin{array}{l}\text { Laceration } \\
\text { repair }\end{array}$ & Patient & $\begin{array}{l}50 \text { available } \\
\text { styles and } \\
\text { artists }\end{array}$ & During & $\begin{array}{l}\text { Pain, anx- } \\
\text { iety, and } \\
\text { physiological }\end{array}$ & VAS/STAI & $38(19: 19)$ \\
\hline $\begin{array}{l}\text { McLeod } \\
(2012)\end{array}$ & Scotland & $\begin{array}{l}\text { Such } \\
\text { as scar } \\
\text { revision, } \\
\text { excision of } \\
\text { benign skin } \\
\text { lesions, } \\
\text { excision of } \\
\text { moles, skin } \\
\text { grafting, } \\
\text { and hand } \\
\text { surgery }\end{array}$ & Patient & $\begin{array}{l}\text { Easy listening } \\
\text { music, classical } \\
\text { music, relax- } \\
\text { ation music, } \\
\text { and contempo- } \\
\text { rary music }\end{array}$ & During & Anxiety & $\mathrm{NA} / \mathrm{STAI}$ & $80(40: 40)$ \\
\hline $\begin{array}{l}\text { Sadideen } \\
\text { et al (2012) }\end{array}$ & England & $\begin{array}{l}\text { Local } \\
\text { anesthetic } \\
\text { procedures } \\
\text { (trauma } \\
\text { and elec- } \\
\text { tive cases) }\end{array}$ & $\begin{array}{l}\text { Research } \\
\text { group }\end{array}$ & $\begin{array}{l}\text { Classics and } \\
\text { easy listening } \\
\text { tracks }\end{array}$ & During & $\begin{array}{l}\text { Anxiety and } \\
\text { respiratory } \\
\text { rate }\end{array}$ & NA/VAS & $96(48: 48)$ \\
\hline $\begin{array}{l}\text { Ghezeljeh } \\
\text { et al (2017) }\end{array}$ & Iran & $\begin{array}{l}\text { Procedures } \\
\text { for the } \\
\text { care of } \\
\text { burned } \\
\text { patients' } \\
\text { wounds }\end{array}$ & Patient & $\begin{array}{l}\text { Persian classic } \\
\text { music but with- } \\
\text { out lyrics and } \\
\text { composed by } \\
\text { Persian music } \\
\text { maestros }\end{array}$ & $\begin{array}{l}\text { Preoper- } \\
\text { ative; } 20 \\
\text { min once } \\
\text { a day for } \\
3 \text { consec- } \\
\text { utive days } \\
\text { before } \\
\text { wound } \\
\text { care pro- } \\
\text { cedures }\end{array}$ & $\begin{array}{l}\text { Pain and } \\
\text { anxiety }\end{array}$ & VAS/VAS & $92(46: 46)$ \\
\hline
\end{tabular}

Abbreviations: STAI, State-Trait Anxiety Inventory; VAS, Visual Analogue Scale.

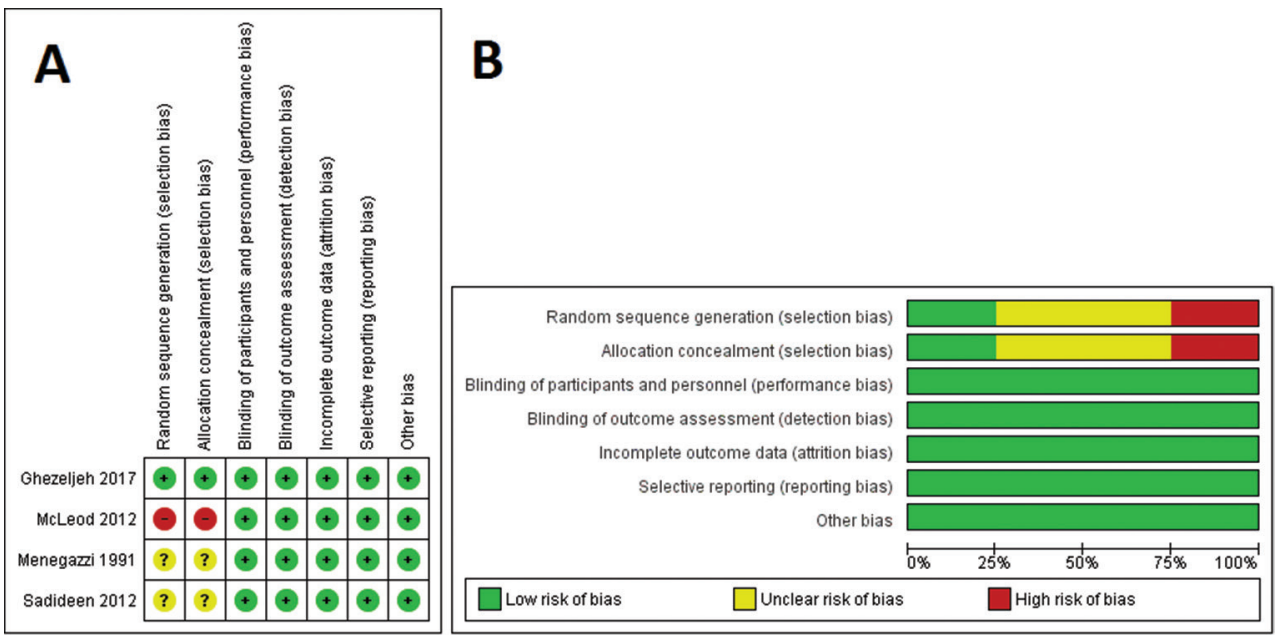

Fig. 2 Risk of bias: (A) within studies; (B) among studies.

when the music was played for patients under general anesthesia; however, they did find it in pain and anxiety. They also revealed that the effect was stronger when the music was selected by patients.

The postoperative period is as important as preoperative and perioperative periods. Playing music is an intervention that apparently improves the patient experience along all the operative processes. In addition to the effects on patients, a benefit on surgical closures was observed in a randomized study performed by Lies and Zhang. ${ }^{22}$ They assessed the time to perform layered closures on pigs' feet and their quality in a group of plastic surgery residents (from the first to 


\begin{tabular}{|c|c|c|c|c|c|c|}
\hline $\begin{array}{l}\text { Outcome. Anxiety } \\
\text { Author, Year }\end{array}$ & MDV & tariance & & & Weights \% & SMD $[95 \% \mathrm{Cl}]$ \\
\hline Ghezeljeh, 2017 & -6.2 & 0.25 & $\longmapsto$ & & $24.65 \%$ & $-6.20[-7.18,-5.22]$ \\
\hline McLeod, 2012 & -2.62 & 0.09 & & - & $25.54 \%$ & $-2.62[-3.22,-2.02]$ \\
\hline Menegazzi, 1991 & -4.5 & 0.37 & $\longmapsto$ & 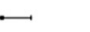 & $24.02 \%$ & $-4.50[-5.69,-3.31]$ \\
\hline Sadideen, 2012 & -1.4 & 0.05 & & 불 & $25.78 \%$ & $-1.40[-1.85,-0.95]$ \\
\hline \multirow[t]{3}{*}{ RE Model } & & & & & $100.00 \%$ & $-3.64[-5.72,-1.56]$ \\
\hline & & Г & $T$ & 1 & ᄀ & \\
\hline & & -8 & -6 & -2 & 0 & \\
\hline
\end{tabular}

Fig. 3 Meta-analysis of included studies. Outcome: anxiety.

sixth year). They demonstrated a decreased in time to perform closures and a higher quality of the result. Therefore, with the available evidence, we might say that music has a beneficial effect on both patients and surgeons.

With the available data, we suggest playing music before and during plastic surgery procedures, because it is a safe and free intervention which improves both patient and surgeon experiences. Regarding the type of music to play, we might suggest playing a soft and relaxing music during the preoperative period and the patient's choice of music during the procedure.

The main strength of our study was including good-quality clinical trials, which allowed us to establish a difference in anxiety between the two groups and suggest playing music in operating rooms. On the other hand, there are many limitations, and they do not necessarily indicate weak methodology, as these were the only available data, some of them are: the limited number of studies, the unclear risk of bias in some topics, not possible to perform a metaregression with the available data. Our primary outcomes are under a subjective evaluation but this is the important outcome to asses, a decrease in objective values is not important if it is not reflected in the same way in anxiety and pain. The main limitation is the heterogeneity between included patients, but we think that in a homogeneous population better results could be achieved.

\section{Conclusion}

Playing music is a safe and free intervention that could diminish anxiety in patients who undergo plastic surgery procedures. In this study no differences were found in pain and physiological variables; however, we recommend performing clinical trials with larger sample sizes because the small number of clinical trials could assess these kinds of outcomes.

\section{Funding}

The authors declare no funding.

\section{Ethical Approval}

No ethical approval required. This systematic review and meta-analysis met all ethics requirements according to the Helsinki declaration and all international statements.

\section{Informed Consent}

Not applied for this work.

\section{Conflict of Interest}

The authors declare no conflict of interest.

\section{References}

1 Li J, Zhou L, Wang Y. The effects of music intervention on burn patients during treatment procedures: a systematic review and meta-analysis of randomized controlled trials. BMC Complement Altern Med 2017;17(1):158

2 Marwick C. Leaving concert hall for clinic, therapists now test music's 'charms' JAMA 1996;275(4):267-268

3 Salimpoor VN, Benovoy M, Larcher K, Dagher A, Zatorre RJ. Anatomically distinct dopamine release during anticipation and experience of peak emotion to music. Nat Neurosci 2011;14(2):257-262

4 Dobek CE, Beynon ME, Bosma RL, Stroman PW. Music modulation of pain perception and pain-related activity in the brain, brain stem, and spinal cord: a functional magnetic resonance imaging study. J Pain 2014;15(10):1057-1068

5 Evans D. The effectiveness of music as an intervention for hospital patients: a systematic review. J Adv Nurs 2002;37(1):8-18

6 Hoffman J. Tuning in to the power of music. RN 1997;60 (6):52-54

7 Simavli S, Kaygusuz I, Gumus I, Usluogulları B, Yildirim M, Kafali H. Effect of music therapy during vaginal delivery on postpartum pain relief and mental health. J Affect Disord 2014;156:194-199

8 Ovayolu N, Ucan O, Pehlivan S, et al. Listening to Turkish classical music decreases patients' anxiety, pain, dissatisfaction and the dose of sedative and analgesic drugs during colonoscopy: a prospective randomized controlled trial. World J Gastroenterol 2006;12(46):7532-7536

9 Vetter D, Barth J, Uyulmaz S, et al. Effects of art on surgical patients: a systematic review and meta-analysis. Ann Surg 2015;262(5):704-713

10 van der Heijden MJE, Oliai Araghi S, van Dijk M, Jeekel J, Hunink MG. The effects of perioperative music interventions in pediatric surgery: a systematic review and meta-analysis of randomized controlled trials. PLoS One 2015;10(8):e0133608

11 Wang MC, Zhang LY, Zhang YL, Zhang YW, Xu XD, Zhang YC. Effect of music in endoscopy procedures: systematic review and meta-analysis of randomized controlled trials. Pain Med 2014;15(10):1786-1794

12 Hole J, Hirsch M, Ball E, Meads C. Music as an aid for postoperative recovery in adults: a systematic review and meta-analysis. Lancet 2015;386(10004):1659-1671

13 Zapata-Copete J, Cordoba-Wagner MJ, García-Perdomo HA, Role of Music in Plastic Surgery Setting: Protocol of Systematic Review and Meta-analysis [Internet]; 2017. Available at: https://doi.org/10.6084/m9.figshare.5554762. Accessed August 7, 2019

14 Higgins JP, Green S, Cochrane Handbook for Systematic Reviews of Interventions: Cochrane Book Series. Chichester: John Wiley and Sons; 2008

15 R Core Team, R: A Language and Environment for Statistical Computing. Vienna: R Foundation for Statistical Computing; 2017

16 Menegazzi JJ, Paris PM, Kersteen CH, Flynn B, Trautman DE. A randomized, controlled trial of the use of music during laceration repair. Ann Emerg Med 1991;20(4):348-350 
17 McLeod R. Evaluating the effect of music on patient anxiety during minor plastic surgery. J Perioper Pract 2012;22(1):14-18

18 Sadideen H, Parikh A, Dobbs T, Pay A, Critchley PS. Is there a role for music in reducing anxiety in plastic surgery minor operations? Ann R Coll Surg Engl 2012;94(3):152-154

19 Ghezeljeh TN, Mohades Ardebili F, Rafii F, Haghani H. The effects of patient-preferred music on anticipatory anxiety, post-procedural burn pain and relaxation level. Eur J Integr Med 2017;9:141-147
20 Ni C-H, Tsai W-H, Lee L-M, Kao C-C, Chen Y-C. Minimising preoperative anxiety with music for day surgery patients - a randomised clinical trial. J Clin Nurs 2012;21(5-6):620-625

21 Updike PA, Charles DM. Music Rx: physiological and emotional responses to taped music programs of preoperative patients awaiting plastic surgery. Ann Plast Surg 1987;19(1):29-33

22 Lies SR, Zhang AY. Prospective randomized study of the effect of music on the efficiency of surgical closures. Aesthet Surg J 2015;35(7):858-863 